\title{
VARIATIONS OF BODY TEMPERATURE AND METABOLISM DURING ENTRANCE INTO COLD LETHARGY IN THE BAT MYOTIS MYOTIS
}

\author{
by \\ GERHARD HELDMAIER \\ Max-Planck-Institut für Verhaltensphysiologie, Erling-Andechs, B.R. Deutschland
}

Bats of temperate zones which hibernate during winter become cold-lethargic during their diurnal rest time even in summer. At the end of their nocturnal activity period they show a drop in body temperature close to ambient temperature $(M$. myotis, cf. Pohl, 1961). This takes place periodically even if the bats are kept in constant darkness (Eptesicus fuscus and Myotis lucifugus, cf. Menaker, 1959, 1961). The daily drop in body temperature is not simply the result of one single reduction in heat production, but seems to be a more complicated process since EKG-records during entrance into cold lethargy (Kulzer, 1967) showed increases and decreases in heart frequency which can be related to a regulatory activity of the sympathetic nervous system.

Normothermy, with body temperatures at about $37^{\circ} \mathrm{C}$, and even lethargy, with body temperatures close to ambient temperature, are both levels with more or less precisely regulated body temperature. Entrance into cold-lethargy may be the process during which the thermoregulatory level is changing from normothermy to lethargy, and the EKGvariations may be related to this change in thermoregulation. In order to obtain more data on thermoregulation during entrance into cold-lethargy, $\mathrm{O}_{2}$-consumption, $\mathrm{CO}_{2}$-production, and two different body temperatures were measured in Myotis myotis. One of the temperature records was taken from the interscapular region to measure thermogenic activity of the interscapular brown adipose tissue.

\section{METHODS}

M. myotis were taken from a summer place under the roof of an old castle in South-Germany. In the laboratory they were kept in groups of two bats in small cages under natural photoperiodic conditions at room temperature, and they were fed every two days with water and mealworms.

For each experiment, the bats were implanted subcutaneously with two thermocouples to measure temparature in the interscapular region and on the back in the region of the hip joints. Both thermocouples (copper-constantan) were insulated with a commercial adhesive and were then placed together in a surgical polyethylene tubing (PE 10). The tubing with the two thermocouples was implanted into the unanaesthetized bat through a small incision in the neck and it was fixed with adhesive on the skin.

After this preparation the bat was placed in a small metabolism box $(5 \times 5 \times 10 \mathrm{~cm})$ in which it could hang and move around with the implanted thermocouples. During the experiment the bats were kept up to five days without food in this box in a cabinet at constant temperature and constant darkness. $\mathrm{O}_{2}$-consumption and $\mathrm{CO}_{2}$-production was measured with an open-circuit system (Hartmann \& Braun, Frankfurt/Main) with a small lag time $(20-30 \mathrm{sec}$, further details are described in Heldmaier, 1970). All $\mathrm{O}_{2}$ and $\mathrm{CO}_{2}$ volumes measured were corrected to standard temperature and pressure conditions.

\section{RESULTS AND DISCUSSION}

The circadian variation of subcutaneous back temperature in one $M$. myotis is shown in fig. 1 . It aroused spontaneously each subjective evening and raised its body temperature from lethargy $\left(23^{\circ} \mathrm{C}\right)$ to normothermy $\left(35-38^{\circ} \mathrm{C}\right)$, and each subjective morning it entered again into coldlethargy. This entrance into cold-lethargy was not only a passive drop in body temperature at the end 

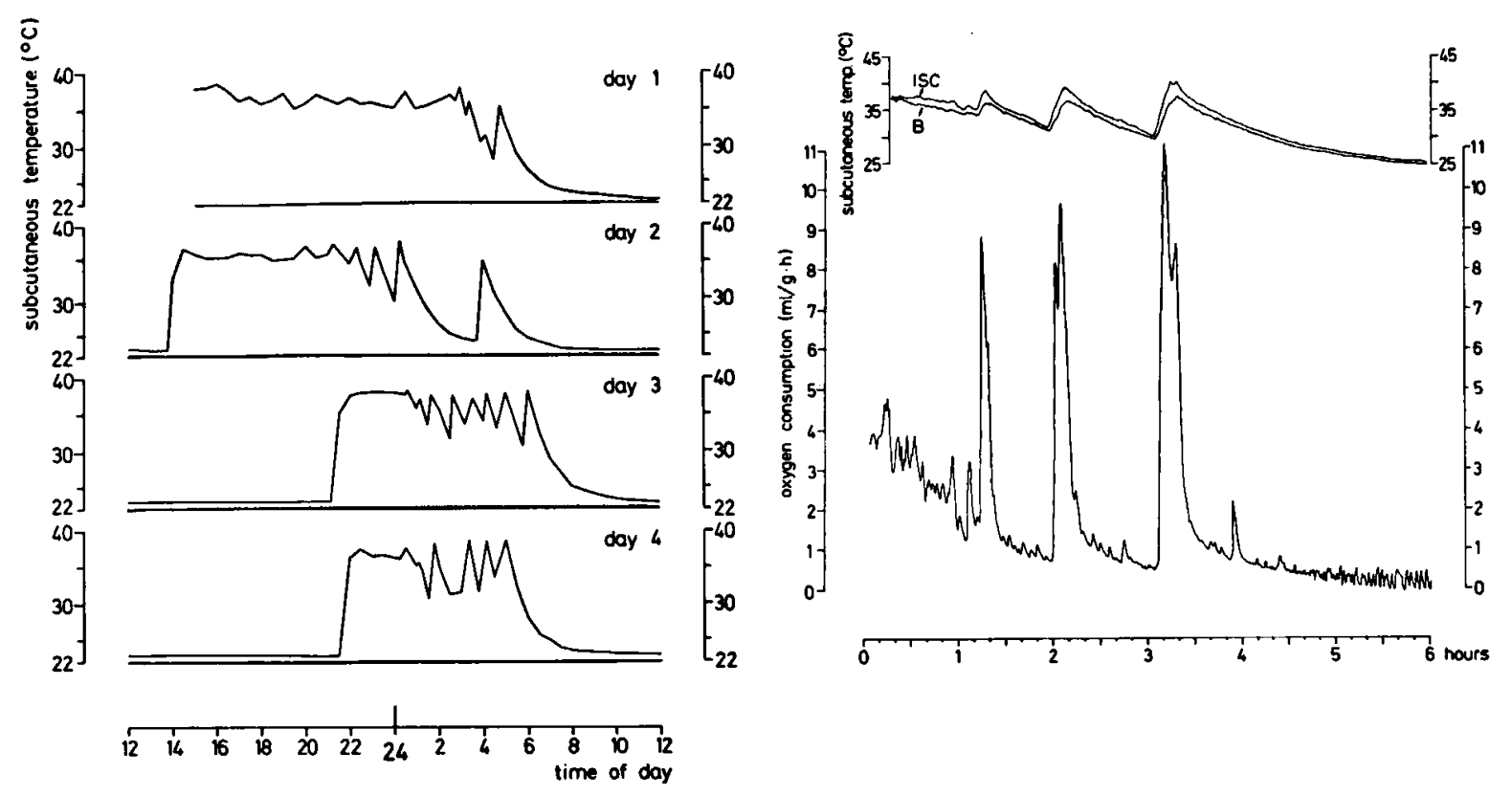

Fig. 1. Variations in body temperature (subcutaneous on the back) of $M$. myotis in constant darkness at $22^{\circ} \mathrm{C}$ ambient temperature. 14. VI.-18. VI. 1969.

Fig. 2. Entrance into cold-lethargy in $M$. myotis at $22^{\circ} \mathrm{C}$ ambient temperature. ISC $=$ interscapular temperature, $\mathrm{B}=$ temperature from the back.

\section{interscapular subcutaneous difference between oxygen- $\quad R Q$ temperature $\left({ }^{\circ} \mathrm{C}\right)$ interscapular and consumption}
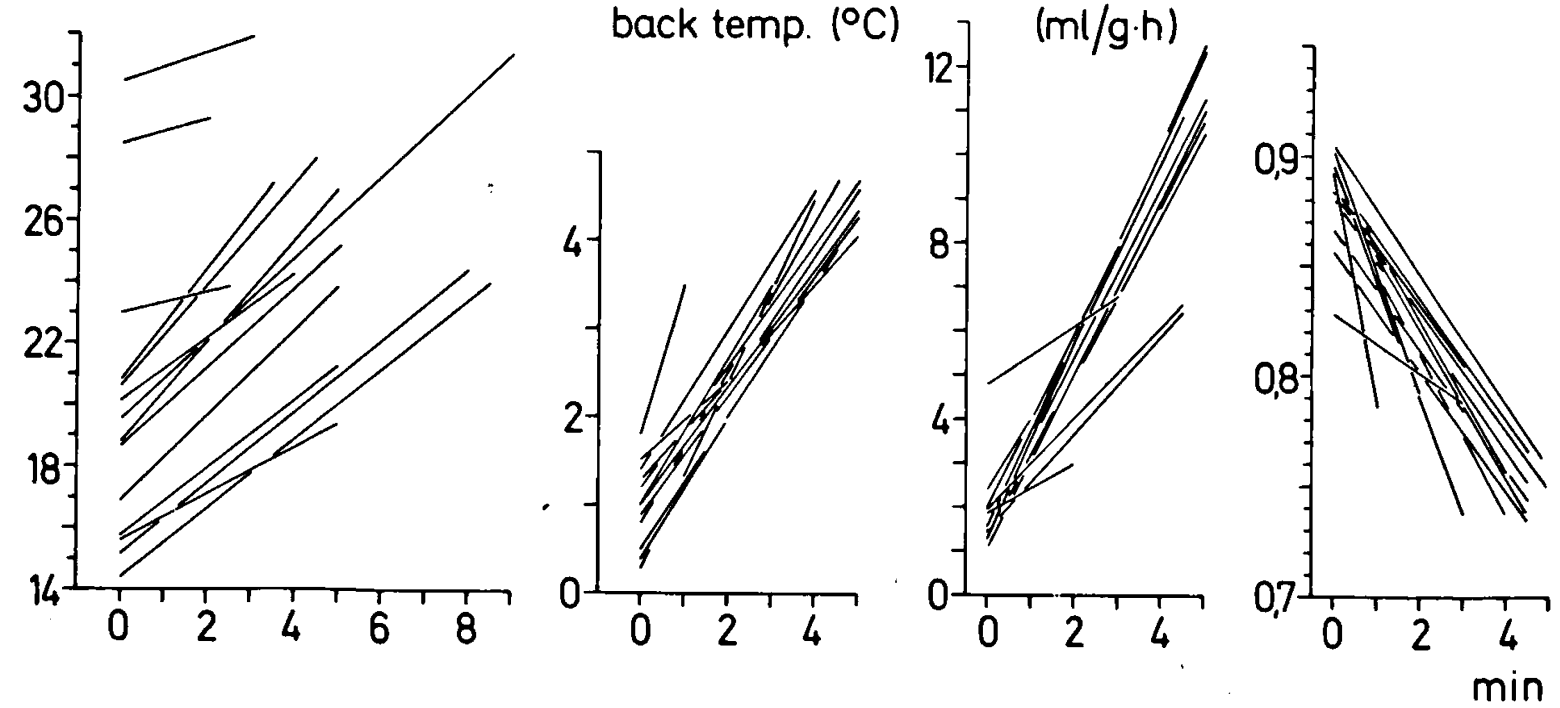

Fig. 3. Temperature and metabolic characteristics of peaks during entrance into cold-lethargy. Measurements on one individual at $5^{\circ} \mathrm{C}$ ambient temperature. The bars connect previous minimum and maximum of one peak. 
of activity. It started with characteristic temperature variations during which the subcutaneous temperature of the back was lowered to about $30^{\circ} \mathrm{C}$ and then increased again to $37^{\circ} \mathrm{C}$. Similar increasing and decreasing steps were repeated up to seven times before the final drop in body temperature occurred. In 13 entrances into cold-lethargy from three individuals at about $20^{\circ} \mathrm{C}$ ambient temperature the total duration of entrance averaged about $6.8 \mathrm{~h}$, and the first $3.0 \mathrm{~h}$ of this time were spent in the active phase of temperature variation, which averaged 5.2 temperature peaks.

Accompanying these variations in body temperature, large variations in metabolism also occurred as demonstrated in fig. 2 . In this record the bat shows an $\mathrm{O}_{2}$-consumption of about $3.6 \mathrm{ml} / \mathrm{g}$.h. during normothermy at $22^{\circ} \mathrm{C}$ ambient temperature, and an oscillatory decrease in $\mathrm{O}_{2}$-consumption to about $2.0 \mathrm{ml} / \mathrm{g}$.h. at the beginning of entrance into cold lethargy. Thereafter, a very fast increase and decrease in $\mathrm{O}_{2}$-consumption occurred ("metabolic peak") which lasted about $10 \mathrm{~min}$ utes. After a further lowering in basal $\mathrm{O}_{2}$-con- sumption another two metabolic peaks were observed and following the last and highest peak metabolism decreased slowly to the lethargic level.

Each of these metabolic peaks was accompanied by an increase in body temperature which occurred faster in the interscapular region than on the back, so that a temperature difference of $3-4^{\circ} \mathrm{C}$ developed between these two sites of the body. The rapid rise in interscapular temperature is interpreted as an increased heat production of the interscapular brown adipose tissue.

The diagrams of fig. 3 contain the changes in temperature and metabolism of all metabolic peaks observed during one entrance into cold lethargy at $5^{\circ} \mathrm{C}$ ambient temperature. These diagrams show a positive correlation between interscapular temperature and $\mathrm{O}_{2}$-uptake in all metabolic peaks. In addition to the rise in $\mathrm{O}_{2}$-consumption, the $\mathrm{RQ}$ dropped during each peak to values near 0.75 , indicating a stimulation of lipid oxidation. An increased $\mathrm{O}_{2}$-consumption, combined with a lowered $R Q$ and with a specific increase in interscapular temperature has been shown to be typical for non-

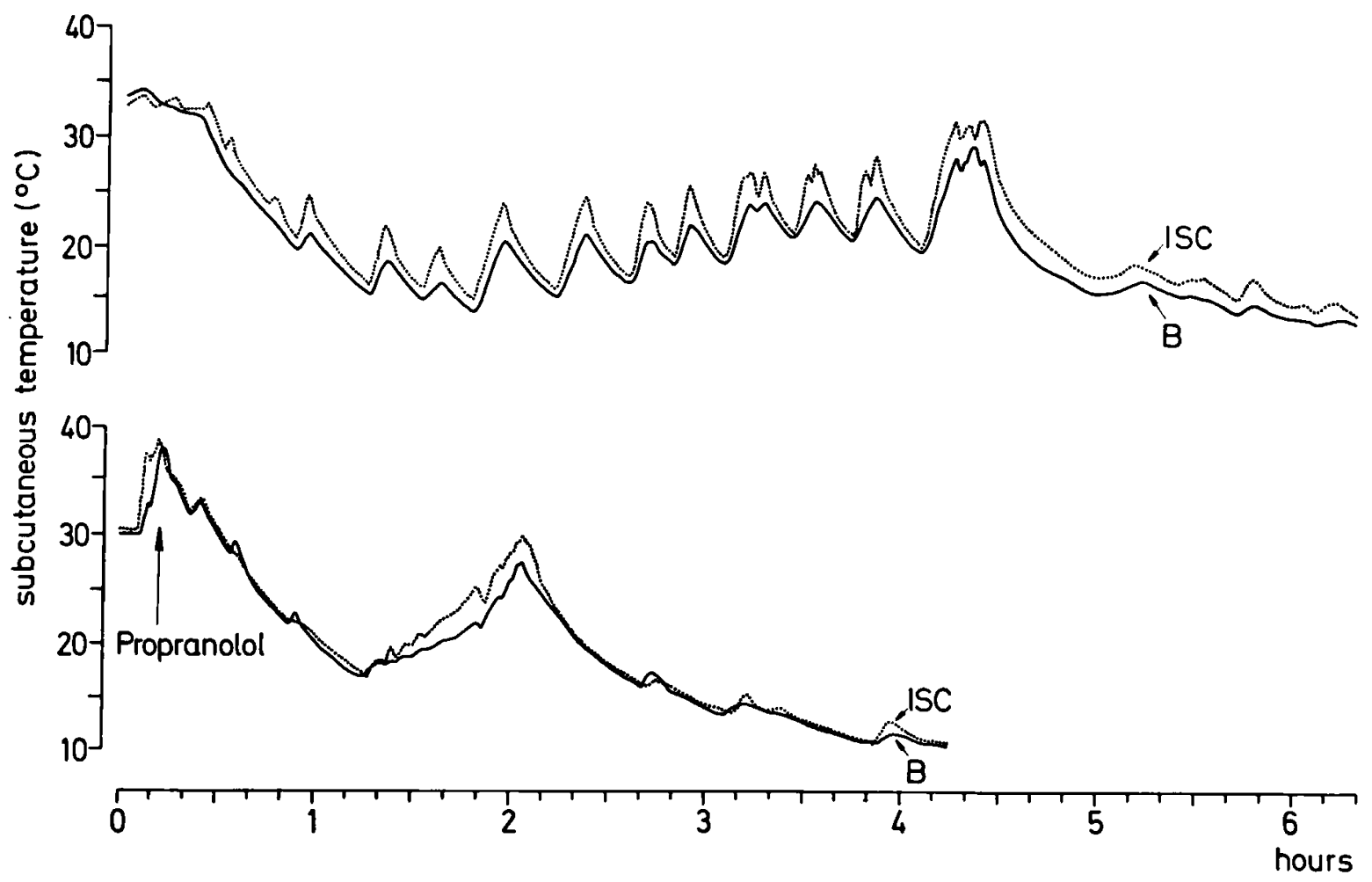

Fig. 4. Infiuence of blocking the adrenergic $\beta$-receptors with Propranolol ("Dociton", ICI, $6 \mathrm{mg} / \mathrm{kg}$, i.p.) on entrance into cold-lethargy at $5^{\circ} \mathrm{C}$ ambient temperature. ISC $=$ interscapular temperature, $\mathrm{B}=$ temperature on the back. The records were obtained from the same bat on two consecutive days; on the first day normal entrance (above) and on the second day entrance with Propranolol (below). 
shivering heat production. Therefore, it can be concluded that these great variations in body temperature are at least partly due to short lasting bursts (2-8 $\mathrm{min}$ ) of nonshivering thermogenesis.

Nonshivering thermogenesis is reduced when the adrenergic $\beta$-receptors are blocked by injection of Propranolol (Brück \& Wünnenberg, 1965; Heldmaier, 1969). Such an injection has been performed as a pilot experiment only in one individual (fig. 4). The temperature curves show the entrance into cold-lethargy at $5^{\circ} \mathrm{C}$ ambient temperature on two consecutive days. Entrance into lethargy of the untreated bat occurred with the normal pattern of repeated heating, which was more pronounced in the interscapular region. After the last and highest increase body temperature dropped slowly down to cold-lethargy. On the next day the bat was allowed to drop into cold lethargy after an injection of Propranolol (6 mg/kg i.p.) and in this case the typical entrance pattern could not be seen. The difference between interscapular and back temperature was reduced or even inverted, and only small temperature peaks occurred as signs of repeated heating. (The large increase about $2 \mathrm{~h}$ after injection remains unexplained.)

The EKG-records during entrance into coldlethargy obtained from the same bat species showed a similar pattern of sudden increases and decreases in heart frequency (Kulzer, 1967), which can be well related to the variations in metabolism and temperature from this investigation. This gives evidence that the peaks during entrance into coldlethargy are due to a strong sympathetic activation, similar to the sympathetic activity during heat production in arousal from cold-lethargy (Jansky \& Hajek, 1961; Kulzer, 1967; Heldmaier, 1969).

In the records of temperature and metabolic variations shown before (figs. 1, 2, 4) it could be noticed that, in the beginning of all entrances the distances between peaks and the amplitudes of the peaks were small, and that both these parameters increased in the further process of entrance into cold-lethargy. A survey on all distances between metabolic peaks obtained during entrance into cold lethargy at about $20^{\circ} \mathrm{C}$ ambient temperature (fig. 5) shows that there is a great variation in the timing of these peaks. But in general there is a tendency for the distances between peaks to increase with serial number and probably to reach a plateau after about the 4 th peak.

If metabolism is measured with an equipment

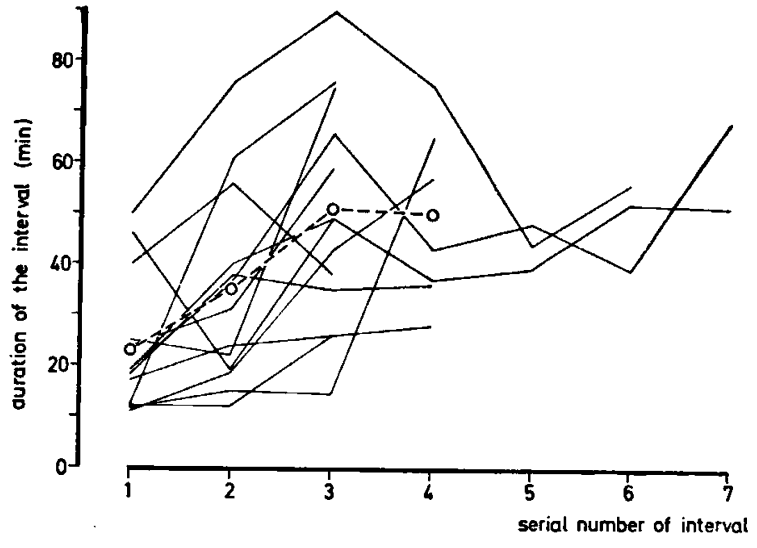

Fig. 5. Intervals between metabolic peaks during entrance into cold-lethargy at about $20^{\circ} \mathrm{C}$ ambient temperature. 3 individuals, 13 entrances; $-=$ single entrance, $\mathrm{O}=$ mean value.

which has a small lag time and good resolution, it becomes evident that there are metabolic peaks not only during entrance into cold lethargy but even during normothermy and lethargy (fig. 6). But these variations were not combined with comparable changes in body temperature at the two sites measured. In normothermy at about $22^{\circ} \mathrm{C}$ ambient temperature, the $\mathrm{O}_{2}$-consumption averaged $3.6 \mathrm{ml} / \mathrm{g}$.h. and varied between 1.3 and 5.6 $\mathrm{ml} / \mathrm{g}$.h. A regularity can be seen in these variations since for instance most of the medium peaks occur at intervals of about ten minutes. During the total time of normothermy the same pattern was always observed. It was only disturbed when longer periods of activity happened which could lead to a rise in $\mathrm{O}_{2}$-consumption without this

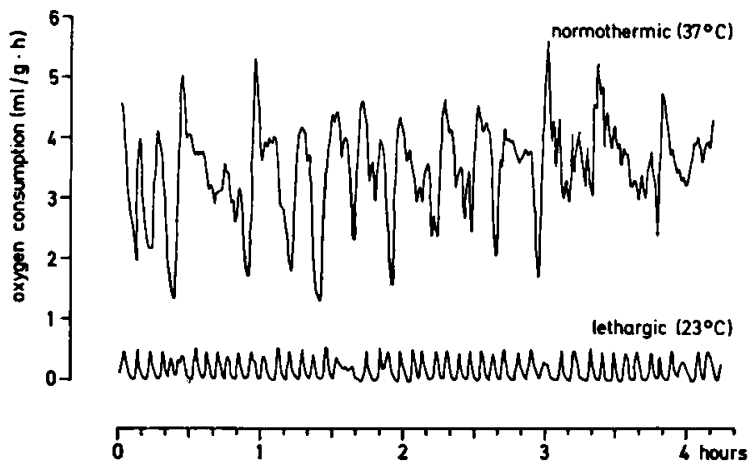

Fig. 6. Variations in $\mathrm{O}_{2}$-consumption of $M$. myotis during normothermy and lethargy at $22^{\circ} \mathrm{C}$ ambient temperature. The records are taken from the same bat as in fig. 2, close before and after this entrance into cold lethargy. 